\title{
Study on the Innovation and Practice of Data Service in Public Library under the Environment of "Internet+"
}

\author{
Li Guo $^{1}$ \\ ${ }^{1}$ Xi'an Aeronautical Polytechnic Institute, Library, Xi'an, Shaanxi, 710089
}

Keywords: Internet+; public library; data services

\begin{abstract}
With the development of Internet, more and more fields have used network technologies to take advantage of the advantages of the Internet, creating more space and more favorable conditions for their own development, and achieving a deep integration of the industry and the Internet. In the current context, public libraries are also updating and innovating themselves. The emergence of new forms of digital resources, electronic reading rooms, and mobile clients has facilitated users' operations in information retrieval, book reading, and other aspects. The majority of users demand for efficiency, service quality and other aspects. How to bring greater public utility to public libraries and make data service innovations is also necessary.
\end{abstract}

\section{Introduction}

The concept of "Internet Plus" was proposed by Prime Minister Li Keqiang in 2015. Domestic scholars also have different interpretations. "Internet+" refers to the application of a new generation of information technology in economic and social life [1]. It uses the Internet's big data, cloud computing, and the Internet of Things to in-depth analyze the needs of customers within the traditional industry, making the Internet and traditional The industry is deeply integrated to drive the development of traditional industries through the Internet. Through the Internet, traditional industries can do a better and more comprehensive control over the information in the industry. Both the supply and demand sides can have a more precise positioning than the past, thus upgrading the traditional industries and promoting the traditional industries. Development and progress.

As a library storage place, the public library can meet people's needs in reading, information search, etc. With the continuous development of the Internet, public library service methods and service types have also undergone major changes. In the past, public libraries mainly used human resources to provide people with various services to meet people's needs. Under the current background of the Internet, many public libraries have launched public micro-signals, official micro-blogs, and mobile client services. 2], to facilitate people more quickly and broadly. Information publishing through new platforms can increase the efficiency and speed of information dissemination, expand the social effects of public libraries, and meet the needs of more users. Users can browse the library's resources at any time on mobile phones, computers, and other network devices to facilitate user information reading and information retrieval, which has produced positive social effects.

The emergence of Internet technology has enriched people's access to information, and the exchange of information between them has become very convenient. There has been tremendous development and progress in both space and time. With the continuous development and advancement of technology, the user's demand for information is also growing. Finding the required information in a timely and accurate manner has become a basic requirement for people in the current society. For libraries, finding the books they need in a huge library system and using the past methods are too complex, time-consuming and labor-consuming, and they can no longer meet the needs of current people. In response to this trend, we will introduce information service technology into public libraries and innovate existing data services to complete our own upgrades and meet customer needs. Under the background of the Internet, China's major libraries have established their own WeChat public account and official Weibo platform to launch their own services and content to the outside world; in the internal construction of libraries, the establishment 
of electronic reading rooms and mobile clients. [3] It is convenient for users to read and review, which greatly improves the efficiency and quality of information services and meets the actual needs of users. This paper focuses on the research on the practice of data service innovation in public libraries under the "Internet + Public Library" environment, and explores the effects of some time innovation initiatives launched by public libraries in the context of the Internet. Further innovations and developments under the "Internet Plus" environment provide relevant suggestions and references.

\section{The Role of Public Library Data Service Innovation Practice}

For the public libraries, the Internet provides information services, big data, and other conveniences. It provides convenient conditions for the introduction of library resources and improves the utilization of resources. Many public libraries design directed reading programs for crowds to meet the needs of these users while facilitating the reading of specific book resources among users, thereby contributing to the improvement of utilization. In addition, by introducing digital resources and providing a mobile service platform, we can target our own resources to more groups and increase the use of resources. The utilization of resources has also been correspondingly improved.

Public libraries have huge book resources. In the process of resource management, there are no good technical conditions, which will affect the management quality and management efficiency, and affect their own development and construction. In the past, public libraries were mainly paper resources. In the context of the Internet, more and more digital books were introduced into libraries. In addition, the emergence of resources such as audio rooms, video resources, and learning courses expanded library resources. The depth of coverage and resources can meet the needs of more users, promote their own technological changes, rely more on network technologies than on human resources, and provide higher quality, more efficient service quality to customers, satisfying Reader's learning needs.

\section{The Measures for Public Library Data Service Innovation Practice under "Internet + "}

Resources are the most basic building components of public libraries. The resources in traditional libraries are based on paper resources and traditional collections of literature resources. This resource system is increasingly unable to meet people's needs. In the age of the Internet, a vast amount of information resources and resources give people more choices and judgments. When people retrieve information, they also choose as much useful information as they need. For traditional libraries, they are Under the constraints of space and other conditions, it cannot provide enough information to users, and gradually can not meet the needs of people in the current era. Under such circumstances, many public libraries have carried out innovations in resource construction, and on the basis of paper-based book resources, they have used the conditions of "Internet Plus" to introduce a large number of electronic resources, such as video resources, "knowledge horizons," and "The digital resources [4], such as the Baixue Foreign Language Academic Search and the "Kurk Music Library," facilitate users to make various choices according to their own needs. In the past, when users browsed library resources, they could not have many options like now. Digital resources gave users enough depth and breadth to meet the needs of most users. In addition, public libraries are also reserved for enthusiasts of paper resources, which meets the different needs of different groups of people. In the experience of resources, digital resources bring new experiences to users. Take the "Kuike Music Library" as an example. In the past, when some users wanted to browse music resources, paper resources could only give users some history about music, music scores, appreciation and the like, while digital resources allow users to listen to relevant songs with their feelings after watching the appreciation of the music, giving users more intuitive experience and experience.

Resource construction is an important part of the development of the public library itself. In the context of "Internet+", the introduction of digital resources and a new upgrade of the library's 
resource system are in line with the trend of the times and can not only attract more The fun brought about by the user experience knowledge has brought new power to its own development. In addition, digital resources are more advantageous than traditional paper resources in the expenditure, preservation and maintenance of funds. Once introduced, they only need to update the latest information in time, which greatly enriches their own resource base.

Under the "Internet Plus" background, the services provided by the public library to the public are also more diverse, not only in terms of quality, but also in terms of efficiency. "Internet + " can use the big data of the Internet to accurately position users' needs. In the introduced digital resource system, it analyzes the user's browsing records to find the relevant content that is most interested in the current user as a later resource. The important part of the introduction can create a more accurate and individualized public cultural service system to meet the practical needs of more people.

During the study, it was discovered that many public libraries used the "Internet+" environment to launch reading promotion for specific groups of people. For example, according to the small readers, they introduced "Children Utopia" [5]. The age range of these readers is mainly 3-8 years old. They are interested in cartoons, comics, etc. in this age group. Their reading ability is relatively poor. To this end, they introduce "Children Utopia” to collect all relevant resources that are suitable for them to read, including paper and digital resources, so that they can have a large number of excellent ones in this age group. Children read books and grow with them. For teenagers, there are ancient and modern Chinese and foreign classics suitable for young people to read; for adults, there are books, workplaces, and other aspects of library resources. On the service content, the public library can conduct a wide range of big data analysis according to different specific groups of people and produce services that meet the users' needs. This not only improves the utilization of resources, but also enhances the overall service quality of the library and gives users more Beautiful reading experience.

With the continuous development of the Internet, the channels for people to obtain information have become more and more extensive, and there have been fewer and fewer acts of visiting public libraries for information review. On the one hand, there are related resources on the Internet. When people need to obtain certain information, they can obtain it through the Internet. Although they are inferior to libraries in quality, they can also satisfy people's needs to a large extent; on the other hand, Because the pace of life is now accelerating, people cannot spend a lot of time visiting public libraries for resources. In this context, in order to avoid the loss of users, public libraries must improve their own spatial structure.

In the past, most of the library's space was occupied by books. Modern libraries have to change this situation and give people more room for exchanges, such as the establishment of discussion and exchange rooms, and the reading of the public library's spatial structure as the main body. Convert to open communication. Under the existing conditions, using the technological advantages of the Internet, public libraries must speed up the construction of new service spaces, set up vinyl auditoriums, high-fidelity stereo surround audio-visual rooms, professional recording studios, and large-scale studios, etc. [6]. On the one hand, the establishment of these service spaces can improve their own service quality. Based on the resource framework, they can create a new spatial structure that is more modern, has better service quality, and has a better user experience based on data resources. All these are users who cannot experience it on the Internet. Such innovative measures need to cost a certain amount of money, but they can attract a large number of users, improve the utilization of their own resources, and make their own book resources "two-dimensional" to "three-dimensional." change.

As a base station for social and cultural services, public libraries have always been practitioners of information technology, social culture, and advanced science and technology. In the context of "Internet+", public libraries must improve their own platform construction, get rid of the shackles of traditional development service models, and integrate deeply with the Internet to create an "Internet+" service platform with readers as their core.

Perfecting the platform construction requires the integration of its own resources. The survey 
found that many public libraries have integrated their audio resources, online course video resources, e-books, newspapers and periodicals in a comprehensive way in the process of building platform innovations, creating a set of online learning, learning management, and learning monitoring. Service center. The main purpose for users to go to the public library is to learn. Such measures cater to the needs of users. The platform that truly meets the needs of users can better satisfy the user's experience and thus provide customers with higher quality services. To create a reader-centered learning service center, readers can use the online registered account information to update the learning progress in real time. The public library platform can track the progress of users' learning, provide intelligent curriculum arrangements and study supervision, and promote readers' conscious learning. Play your own educational function. The creation of a reader-centered learning platform can also help users avoid blindly choosing among a large number of resources and fail to reach the goal of learning [7].

\section{Conclusion}

Promoting the integration of public libraries and the Internet is a necessary choice to achieve the transformation and upgrading of public libraries. Under current conditions, the integration of public libraries and the Internet still has shortcomings in depth and breadth, and accelerate the integration and development between the two. We must speed up innovation in data services, apply innovative measures to practice, test in practice, use the advantages of the Internet as a tool, make up for the disadvantages of public libraries in data management, and build a harmonious and harmonious development system for public books. The library has played a positive role in promoting social and cultural effectiveness and educational effectiveness.

\section{References}

[1] Yang Jing, Liao Zhijiang, Ye Suping. "Internet +" under the university library in the public digital cultural service mode of exploration [J]. Journal of North China University of Technology (Social Sciences Edition), 2017, 17 (06): 48 -51.

[2] Fu Qiumei. The Analysis of the Reform and Innovation of Library Service Model under the Background of "Internet Plus"[J]. Journal of Library and Information Sciences in Agriculture, 2017, 29(09): 173-176.

[3] Zhong Yongwen. On the Transformation and Development of Library Services under the "Internet Plus" Environment[J]. Science and Technology Vision, 2017(22):156-157.

[4] Xu Hui. The prospect of new public libraries in China based on the context of interconnection [J]. Taxation, 2017(10):152-153.

[5] Jin Xiaodong. Research on Personal Service Innovation of Urban Public Libraries under Big Data Thinking[J]. Journal of Library and Information Sciences in Agriculture, 2016,28(11):154-156.

[6] Li Jiaxing, Wang Xixi, Zhang Changliang, Xiang Yi. Research on Library Innovation Service Mode under the "Internet Plus" Environment[J]. Library Science Research, 2016(18):59-63.

[7] Xu Junhua, Yan Shilian. Present situation and suggestions of public lectures in provincial public libraries under the "Internet + " environment[J]. Library and Information Service, 2016, 60(14): 75-83. 